\title{
Assistive Technology as an Accommodation for a Student with Mild Disabilities: The Case of Alex
}

\author{
Darlene Brackenreed \\ Nipissing University
}

\begin{abstract}
This case study investigated the impact of selected types of adaptive and assistive technology (AT) on the learning gains and academic achievement levels of a female student with mild disabilities in her sixth and seventh grades in a Catholic school board in northeastern Ontario. Interviews were conducted with the parent, student, and pre-service teachers. Records from 6 school years were examined to determine the student's academic history and performance levels, and reports from numerous professionals involved in the assessments and interventions of the student were explored. Reports from the community service-learning assignment provided information regarding teaching approaches and student responses. A synthesis of all data suggested that AT had resulted in increased student achievement levels, perceptions of capability, and student self-advocacy. Additionally, the acceptance and use of AT by teachers increased significantly with the training of their student and the student's subsequent tutoring of the teacher and classmates in the use of selected assistive technology.
\end{abstract}

As part of their Special Education class community service-learning assignment in a Bachelor of Education program, two different pre-service education students in consecutive years signed up to work one-to-one with a young girl in Grade 6 and subsequently in Grade 7. Community Service-Learning is a teaching and learning strategy that integrates meaningful community service with instruction and reflection to enrich the learning experience, teach civic responsibility, and strengthen communities. It is intended to change both the receiver and the provider of the service. This is accomplished by combining service tasks with structured opportunities that link the task to self-reflection, self-discovery, and the acquisition and comprehension of values, skills, and knowledge content (Canadian Alliance for Community ServiceLearning, 2007; National Youth Leadership Council, 2007). The purpose of the assignment for the pre-service teachers was to get to know and understand a student experiencing mild disabilities, teach different forms of assistive technology (AT) from which the student could choose her best options, and to understand issues for the student. This article describes the out- 
comes of these relationships over a 2-year period and their impact on the student's selfperceptions and achievement levels.

The government of Canada has adopted the United States' Assistive Technology Act of 1998 definition of assistive technology. AT commonly refers to

...products, devices or equipment, whether acquired commercially, modified or customized, that are used to maintain, increase or improve the functional capabilities of individuals with disabilities. AT service is directly assisting an individual with a disability in the selection, acquisition, or use of an assistive technology device. (para. 1)

For purposes of this article, AT will be delineated further as any technology that enables an individual with mild disabilities to counterbalance specific deficits. It is worth noting that AT is not aimed at fixing or remediating learning difficulties. Rather, it is used as a strategy to compensate for or accommodate areas of difficulty, generally by focusing on an individual's area of strength. Further, AT is not intended to teach or instruct (as is the case with computer-aided instruction), although it can be used to increase access to instruction.

Technology has made significant advances in assisting individuals with disabilities to become independent and productive members of society. Laws mandating civil rights for those with disabilities imply that technology is an important avenue for providing equal access for those with disabilities. For example, the purpose of The Ontarians with Disabilities Act is "to improve opportunities for persons with disabilities and to provide for their involvement in the identification, removal and prevention of barriers to their full participation in the life of the province" (Province of Ontario, 2001, c. 32, s. 1). The concepts of "equal access," "nondiscrimination," and "accommodations," as outlined in the Act, have created an atmosphere that encourages the use of AT to help to improve opportunities for persons with disabilities and to provide for their involvement in the identification, removal and prevention of barriers to their full participation in the life of the province (Ontarians with Disabilities Act, para. 16).

AT is recognized by many experts in the field as holding great promise for students with disabilities (Ashton, 2006; Blackhurst, 1997; Edyburn, 2000; Marino, Marino, \& Shaw, 2006; Patrone \& Pettapiece, 2007). To understand why the potential is so great requires an understanding of the relationships between disability and AT. According to the World Health Organization, International Classification of Functioning, Disability, and Health (World Health Organization, 2001), every person can experience a decrease in health or ability, meaning that all persons can experience some kind of disability. ${ }^{1}$ Disability refers to an impairment of body structure or functioning, a limitation in activities, or a restriction in participation, conceived as a dynamic interaction between health conditions and environmental and personal factors (World Health Organization, 2001, para. 6). Environment includes all aspects of the physical, social, and individual world. Activity limitations are assessed in relation to a particular environment with or without assistance, such as aids or equipment.

A disability, within the realm of special education, refers to a loss or deficit in ability; the focus is not on the deficits within the child, but on the child's strengths and needs and the educational environment that supports the child. The whole child is taken into account, not just the psychological functions of learning. Special needs education encompasses all students who

\footnotetext{
${ }^{1}$ After nine years of international revision efforts coordinated by the World Health Organization (WHO), the World Health Assembly on May 22, 2001, approved the International Classification of Functioning, Disability and Health and its abbreviation of "ICF."
} 
are failing in school or whose progress is hindered for a variety of reasons, not just for those who have been identified as having a disability.

Students with mild disabilities have the potential to experience success in their school careers and beyond. They require specialized interventions appropriate for their individual strengths and needs, such as specific skill instruction, the development of compensatory strategies and self-advocacy skills, and appropriate accommodations such as assistive technology (Province of Ontario, 2001). These students are educated in inclusive environments where their education is differentiated to respond to their diverse needs.

Achieving inclusion and full participation for persons with disabilities requires barrierfree and inclusive designs. Preventing and removing barriers means persons with disabilities should be able to access information and perform duties and requirements with dignity and without obstruction. If barriers continue to exist because it is impossible to remove them at a given point in time accommodations should be provided to the extent possible (Ontario Ministry of Education, 2005). The policy and guidelines on disability and the duty to accommodate from the Ontario Human Rights Commission state,

The duty to accommodate requires that the most appropriate accommodation be determined and then be undertaken, short of undue hardship. The most appropriate accommodation is one that most respects the dignity of the individual with a disability, meets individual needs, best promotes integration and full participation, and ensures confidentiality (n.d., Article 3.3)

Once the functional limitation of a disability is ascertained, an appropriate accommodation can be identified. For example, the requirements of a course are identified and then the difficulties the student is experiencing with the requirements are determined. From this information, AT tools are selected to meet the needs of the person with a disability to perform the essential functions of the course. Accommodations using AT range from low-tech tools (e.g., tape recorders) to high tech electronics (e.g., speech to text software on a computer).

\section{Purpose of the Study}

In this case study, the mentoring of a student by pre-service teachers through community service-learning was designed to serve many purposes. First, it was assumed that mentoring a student by a pre-service teacher would provide one-to-one instruction and support in learning how to use selected AT as an accommodation for mild disabilities. Second, the training in the use of the AT by the pre-service teacher was designed to positively impact the academic achievement levels and the consequent self-concept of the student with a mild disability. Finally, it was assumed that the ability of the student to teach others in the classroom - teacher and peers alike-would have a positive impact on the teacher's ability to ascertain the value of the technology and its use with students; ideally, this would spread to the use of AT from the classroom to the school and ultimately, throughout the school board.

\section{Method}

Borko and Putnam (1998), in their review of learning to teach, noted that "the learning of individuals is a constructive and iterative process in which the person interprets events on the 
basis of existing knowledge, beliefs, and dispositions" (p. 674). This view of learning is built upon understanding change as a dynamic and transformational process. Methodologically, an intensive, descriptive approach, which emphasizes individual participants and variation in the method of collecting data and its analysis with non-manipulation of the naturally occurring research context, was adopted in the present study in the form of a case study. Case study research involves a thorough examination of factors within the context of a single case (Yin, 2003) and can be conducted through a range of research methods, both quantitative and qualitative (Cousin, 2005). A single case study design was chosen to answer how the use of AT with a student experiencing mild disabilities affected her academic performance in order to inform future practice. The findings from the case study will not automatically lead to generalizations; however, a close study of practice will offer valuable insights into how AT can accommodate the learning barriers of students with mild disabilities. Following approval from the Research Ethics Board, the parents consented to the study.

Interviews were conducted with the parent and student. Records from six school years were explored to determine the student's academic history and performance levels. In addition, reports from a school psychologist and occupational therapist involved in the assessments and interventions of the student were examined. Pre-service teachers written and oral reports and discussions of content and teaching strategies, issues, and challenges from their service-learning assignment provided information regarding teaching approaches and student responses. These methods of data collection provided rich material for discussion and a means of triangulation for authenticity.

\section{Participant}

The participant, Alex, was selected from a sample of children who were referred by local schools for a pre-service teacher through the community service-learning component of a special education class in a teacher education program. Alex was 12 years old and in Grade 7 in a Catholic public school in northeastern Ontario at the time of the study's completion. Regarding socioeconomic status, both of her parents had graduated from university and are professionals working in the community.

Alex's school followed the mainstream curriculum of Ontario, including reading and the teaching of composition writing that was targeted in this study. Alex was 11 years and 2 months of age at the start of the study and had not failed a grade in school. She had received assistance from a resource teacher and educational assistant for 30-60 minutes a day beginning in the second term of Grade 1. Despite this special attention, her reading and writing skills had not developed beyond the second grade. The teachers at Alex's school were resistant to the idea of AT as an accommodation and viewed it as cheating and unfair to other students. Additionally, the teachers had not learned how to use the AT that was present in the school and expressed time constraints and lack of access to training as a major problem in learning the technology. During the study, Alex did not receive extra help from the resource teacher or educational assistant. Before the intervention, the parents and student were interviewed and documents provided by the parent were examined and synthesized. 


\section{Procedure}

The study took place when Alex was in the sixth and seventh grades. She had been assessed for the purpose of an Identification Placement Review Committee ${ }^{2}$ review three weeks before the intervention on the following: Wechsler Intelligence Scale for Children, Third Edition (Wechsler, 1991); the Dyslexia Assessment Reading Program, Second Edition (Jordan, 2000); the Wechsler Individual Achievement Test, Second Edition (Wechsler, 2001); the Peabody Picture Vocabulary Test, Third Edition (Dunn \& Dunn, 1997); Learning Disability Symptom Checklist (2007); Comprehensive Test of Phonological Processing (Wagner, Torgensen, \& Rashotte, 1999); Conner's Rating Scale (Conners, 1989); the Personality Inventory for Youth (Lachar \& Gruber, 1995); and an Occupational Therapy Writing Assessment (Ministry of Children and Youth Services, 2006). A school psychologist and an occupational therapist conducted the assessments.

Assessment information. From a psychological assessment in Grade 4, it was determined that Alex functioned within the low average range of intellectual ability, demonstrating substantial deficits in nonverbal tasks and attention ability. She experienced developmental delays in visual recognition memory, visual processing, and slower cognitive processing on tasks of executive function, such as organization and planning.

Alex demonstrated memory deficits, such as being unable to remember what she had just seen or heard and poor sight vocabulary, spelling, inconsistency, and limited receptive and expressive language. Related to memory, Alex made the same mistake repeatedly and appeared not to benefit from repetition. Auditory registration, short-term memory, sequential memory, active working memory, and retrieval were all relatively well developed.

With respect to visual processing, there were noted to be significant areas of developmental deficit in most areas assessed for Alex. Visual-motor integration difficulties were evidenced by the fact that she appeared to be clumsy. Difficulties with visual vigilance and visual-spatial awareness were indicated by a poor sense of direction, and visual pattern recognition and visual problem-solving presented barriers to learning for Alex. Alex had difficulty with black on white contrast and used an Irlen lens to facilitate reading.

Difficulties with academic skills were noted in the areas of reading and writing. Overall, it was determined that she was functioning between the $1^{\text {st }}$ and $2^{\text {nd }}$ percentiles. With respect to reading skills, she was two or more years delayed in letter and word recognition, phonological processing, and reading comprehension. These results revealed close to 2 standard deviations of discrepancy between reading skill development and intellectual potential and are consistent with the characteristics of a reading disability. A writing disability was identified through handwriting problems or dysgraphia and spelling skills at the $1^{\text {st }}$ percentile.

Learning disability screening data indicated visuoperceptual difficulties were evidenced by Alex's tendency to erase her work excessively, reverse letters, complain about blurred print, lose her place frequently while reading, and demonstrate lethargy in noting similarities and differences in words or noticing changes in her environment. She experienced greater success with large print materials and materials with fewer items on the page.

Further testing with the Dyslexia Assessment Reading Program revealed that Alex exhibited low to moderate symptoms of visual dyslexia, moderate symptoms of dyslexia, and low to

\footnotetext{
${ }^{2}$ In Ontario, exceptional pupils are identified as such by an Identification, Placement, and Review Committee according to Regulation 181/98 (Ontario Ministry of Education, 1998).
} 
moderate scotopic tendencies. Scotopic tendencies include such things as losing her place while reading and writing, reading in low or indirect light, and experiencing the Rivers effect (e.g., Finallythelongjourney wasover.Luis andMAri aheld). She also experienced some fading in and out of the printed text while reading. Borderline symptoms were evident in auditory dyslexia. Dyseidesia, which Alex to be a slow reader with overreliance on phonetic decoding and to have difficulty decoding sight words, was noted.

It also was noted that Alex did not appear to be a strategic learner - a common trait of students who have learning difficulties. Further, it was suggested that she might have been more receptive when strategies were demonstrated by others rather than directly given to her. Preferential seating, monitoring of fatigue, consideration for her difficulty in copying notes, and development of keyboarding skills on a computer were highly recommended by the psychologist.

Alex's parents expressed concern over signs of anxiety that Alex began to demonstrate in regard to learning; for example, she had expressed specific fears about doing something wrong in the classroom in front of her teacher and peers. She had particular anxiety in demanding educational environments where she did not perceive there to be sufficient support. Anxiety tendencies were confirmed through the completion of the Conner's Rating Scale and the Personality Inventory for Youth.

Occupational therapy assessment indicated challenges with printing due to a difficult pencil grasp; increased pencil pressure; decreased printing speed; difficulties with spelling and grammar; hand pain with increased written output; and variable sizing, spacing, and baseline orientation. Use of a pencil grip was strongly encouraged to help decrease pressure and reposition her fingers for more refined movements. Further testing indicated that Alex had the motor ability to use her pencil effectively, but experienced difficulty reproducing what she saw visually, most likely as a result of how she processed complex visual information; copying from an overhead or board was a slow, laborious chore for her. The occupational therapist recommended that Alex learn to use Word $\mathrm{Q}^{3}$ and a headset microphone for writing aids together with an Alphasmart $\mathrm{Dana}^{4}$ for taking notes and beginning seatwork in class. The latest Individual Education Plan and Identification, Placement, Review Committee further recommended accommodations of AT such as Word Q and SpeakQ, Kurzweil 3000, TextHelp! Read and Write 6, or Dragon Naturally Speaking. The difficulty with the recommendation for AT was that none of the professionals involved with Alex's educational experiences appeared capable of understanding or teaching the applications to Alex prior to the study.

Intervention. A pre-service teacher was assigned to work with Alex during a Special Education Additional Qualifications course in May and June of 2005. The teacher candidate, Mandy, was a highly energetic and positive individual who had just completed her Special Education/Educational Psychology class during her Bachelor of Education program. During this class, each student participates in an assistive technology assignment whereby he or she teaches an individual how to use one of three choices of assistive technology. Mandy had become quite proficient in her use of Dragon Naturally Speaking, Kurzweil 3000, and TextHelp! Read and Write 6, and eagerly agreed to teach Alex and her mother how to use the programs based on the occupational therapist's recommendations.

\footnotetext{
${ }^{3}$ Word Q is a software tool used along with standard writing software. It suggests words to use and provides spoken feedback. A special text reader helps with proofreading.

${ }^{4}$ Alphasmart Dana is a durable, portable, affordable alternative to laptops and PDA's.
} 
During the first two weeks immediately following the completion of each of Alex's training sessions - on the use of the selected assistive technology in the first year and twice each semester in the second year of the study-Alex's parents shared classroom achievement indicators, report card, teacher observations, Alex's attitudes toward AT, and their insights on the impact of the AT on her achievement levels and attitudes. The pre-service teacher reported on a weekly basis during the intervention, and the final report was analyzed and synthesized into conclusions triangulated by the other data collected. Alex's mother was involved in each of the training sessions and took numerous notes so that she would be able to assist Alex when the pre-service teacher was not available; in this way, Alex's difficulty with memory was addressed and the AT was practiced between visits.

During the initial meeting in year one of the study during May and June, Mandy assisted Alex in understanding the difficulties that she experienced when reading and writing. From this discussion, Alex identified common difficulties that she experienced when reading and writing and described the different strategies that she had tried and an indication of her perceptions of lack of success in using them. Strategies that had been employed at the school were high interest low vocabulary reading materials, large print with fewer words on a page, an Eschenbach Bright Field Magnifier, books on audiotape, a peer buddy, extra time for work completion, oral testing, and the use of a scribe.

During the second meeting, Mandy introduced Dragon Naturally Speaking to Alex, modelled its use, and assisted Alex in training the program to recognize her voice. This training takes about 20 minutes to complete and requires assistance for students with a reading disability because the passages it requires them to read are written above their reading level. The pre-service teacher had been taught to whisper the passage, chunked appropriately, into Alex's ear for her to repeat aloud.

During their third session together, Alex already started to use Dragon Naturally Speaking for some of her schoolwork and said that she liked it. She reported that background noise sometimes interfered with the microphone and caused the program not to recognize her words, so when her little brother yelled in the background it was very annoying. Mandy and Alex spent this session and the next going through the writing process and using Dragon Naturally Speaking to write composition assignments from school.

Mandy introduced TextHelp! Read and Write 6 the next time they met. The main purpose of the activity was to expose Alex to the new technology and to get a sense of whether she felt that a text reader would help with her assigned readings. Based on Alex's enthusiastic response, it was decided by the researcher and Alex's mother that she should begin to learn Kurzweil 3000 in preparation for secondary school; it is a large program with numerous capabilities well-suited for secondary school students, but takes considerable time and practice to master. In the meantime, Alex used TextHelp! Read and Write 6 on a daily basis because it was substantially easier to master. Mandy spent their final four sessions assisting Alex to master TextHelp! Read and Write 6, apply it to her schoolwork, and begin learning selected portions of Kurzweil 3000.

Mandy graduated from the Bachelor of Education program, and in September Alex continued her sessions with a new pre-service teacher named Sherry. Sherry was keenly interested in special education and assistive technology and had elected the Community Service-Learning assignment for her Special Education/Educational Psychology class during her Bachelor of Education program.

As previously noted, subsequent to the training sessions with Dragon Naturally Speaking, TextHelp! Read and Write 6, and Kurzweil 3000, Alex had an assessment with an occupational 
therapist. The occupational therapist recommended that Alex be instructed in the use of Word Q and an Alphasmart Dana. Alex's mother requested that further sessions be spent teaching Alex this software and hardware. Sherry demonstrated Word Q to Alex and pointed out how this program would be beneficial to her. The spoken and print word prediction based on conventional and inventive spelling and text reader appealed to her immediately as she had strength in phonetic decoding and a preferred auditory learning style. They spent the next three sessions learning the program and practised its use with class assignments.

In the remaining sessions, Sherry taught Alex and Alex's mother how to use the Alphasmart Dana, which provided an effective accommodation for Alex's dysgraphia because she could use the keyboard and, thus, no longer had to struggle with handwriting. Having access to the Alphasmart Dana with Word Q at school meant that Alex could participate in class writing assignments because she had the tools she needed to write. Involving Alex's mother in the sessions facilitated the transfer of accommodations for reading and writing from the pre-service teacher sessions to the school environment. Alex's mother and Sherry consulted after each session. Alex's mother, in turn, consulted with the occupational therapist and was able to get the occupational therapist to spend time in the classroom assisting Alex, other students, and the teacher with the Alphasmart Dana and Word Q. With the support from her pre-service teachers and mother, Alex became very confident in her use of AT and began teaching her classmates and teacher how to use it as well.

Immediate, concrete, and continuous feedback was offered regularly. Alex was encouraged to compare her performance and outcomes using AT to those at the beginning of the intervention. In this manner, she was able to monitor and evaluate her own progress. The changes that Alex noted were discussed with her mother, pre-service teacher, and her classroom teacher.

\section{Instruments Used}

Alex's progress and successful applications of AT were assessed through the examination of regular classroom assignments and assessments. Decoding, written composition, and spelling were evaluated. Interviews with Alex, her parents, and her pre-service teachers provided further information on her academic progress and attitudes toward school. Each person was interviewed separately in individual sessions. Interview questions probed teacher, parent, and pre-service teacher views of Alex's ability to effectively use the assistive technology and the ways in which AT was used at school and at home.

\section{Results}

A synthesis of all data suggested that the use of AT had resulted in increased student achievement levels, perceptions of capability, and student self-advocacy. Prior to the introduction of AT, Alex made numerous spelling errors in her daily assignments and classroom assessments: on average, she incorrectly spelled every third word. When using AT, her spelling errors decreased by an average of $80 \%$, indicating a large intervention effect. 


\section{Achievement Levels}

During her initial sessions with her pre-service teacher, Alex incorrectly decoded a 100word passage at a rate of approximately $19 \%$. Her decoding errors decreased by about $80 \%$ with the use of a text reader, indicating a large intervention effect; decoding speed was greatly enhanced with the use of a text reader. Alex took 10 minutes to read a 100 -word passage without the intervention and 5 minutes with the text reader. The length of her compositions remained unchanged.

\section{Perceptions of Capability}

The pre-service teachers interviewed Alex at regular intervals and discovered positive changes in her attitude toward writing: She expressed more interest in writing and considered it easier with the use of AT. Additionally, she described how the AT seemed to be helping her to learn how to spell often-used words: "I see the word on the screen and later when I think of the word I remember how to spell it. Now I know the spelling is right and I learn the right way to spell it."

It proved advantageous, especially with her low vision, for Alex to hear the words as well as to see them. It also quickly became apparent that Alex needed consistency in the applications that she used. In other words, she needed to use the same program at school as the one at home and have continuous, easy access to AT. The AT showed great promise for accommodating Alex's schoolwork, but she needed her school and teachers to be supportive of its use. The difficulty had been that no one at the school had experience or training with AT even though the school had a copy of Kurzweil 3000 sitting on a shelf.

In an interview, Alex's mother described the decreased level of anxiety that Alex demonstrated after the intervention. Rather than resisting assistance from others when she needed help, she now was more independent with her use of AT and regarded the accommodation as "cool," rather than a source of embarrassment. Other students in the class took an interest in the technology and asked her to help them learn it. Alex told her mother that she did not feel weird using the Alphasmart Dana and Word Q because others in her class wanted to use it too. She also said that she felt good about her ability to teach others including her teacher and resource teacher, and that it made her feel good about herself instead of feeling stupid. She knew how to do something that others could not do. It appears that Alex's perceptions of support at school had changed as she told her mother, "It feels so good to get help at school and to be able to do the work that other kids are doing."

\section{Teacher's Responses}

Alex's mother described the teacher's responses to Alex's use of technology: She noted that Alex was enjoying preparing class presentations and reports. She also indicated that Alex displayed a more positive attitude toward reading and writing and demonstrated proficiency in the use of her software and Alphasmart Dana. She explained that the Alphasmart Dana was durable so that she was no longer fretting over students accidentally dropping it or knocking it off a desk. 


\section{Student Self-advocacy}

The teacher asked Alex to teach her how to use the programs and started to encourage other students to use them. Alex's mother was welcomed to the classroom by the teacher to assist Alex and others in the use of AT based on what she had learned during Alex's sessions. Other parents began visiting the classroom to learn about the new technology that had been introduced into the classroom, requesting that their children be given the accommodation of AT to support their learning.

\section{Discussion of the Case Study}

The aim of this study was to introduce the intervention of assistive technology designed to positively impact the academic achievement levels and the consequent self-concept of the student with a mild disability. Additionally, its purpose was to create a positive impact on the teacher's ability to ascertain the value of the technology and its use with students.

Alex's spelling before the intervention was largely undeveloped. During the course of this study her spelling of frequently used words, as measured by daily work, improved. Her inability to recognize incorrectly spelled words resulted in part from her inability to decode words accurately. It is assumed that her improvement in decoding facilitated her improvement in spelling to some degree. Claims about a causal relationship between decoding accuracy and spelling based on this study must be viewed with caution. Follow-up with more measurements using time-series analysis where the time-dependent relationship between decoding and spelling could be tracked is needed.

Students with reading and writing difficulties tend to be unwilling to read their own texts (Graham \& MacArthur, 1988). It may be that they become anxious and stressed as they become more aware of their difficulties and have to spend more time on a difficult and disliked task. In contrast, Alex was willing to read what she wrote when using Word Q, as it read the passage aloud to her through the use of the text reader. She also engaged in text revisions as a result. On the basis of spelling in her school assignments she progressed in her spelling of frequently used words.

By involving the parent and teacher in the project it was assumed that learning transfer would be facilitated from the pre-service teacher-student training sessions to the classroom. Alex's mother was highly motivated to participate in the study: She volunteered to take part in the intervention study and readily agreed to the concept of AT as an accommodation.

Alex's teacher actively asked questions about the applications of AT and specific questions in learning the program and how to use the Alphasmart Dana. She asked Alex to teach her and others in the classroom how to use the program and offered the accommodation to other students. In light of these observations, whole-class teaching, where the identified student and the other students in the class can learn new strategies together, can achieve similar results in an environment of acceptance on the part of the teacher. In this study, the benefits of Alex teaching others were her decreased anxiety and a perceived increase in status in the eyes of her teacher and classmates. Positive attitudes developed towards reading and writing reflecting an increase in self-esteem for Alex.

One of the exciting aspects of Alex's growth in the use of AT was her willingness to teach others, including her teachers, how to use the programs. Not only did this teaching consoli- 
date her own learning, but it provided an opportunity for Alex to build self-esteem through her ability to use and teach technology to her peers and teacher. Her image changed from being a student who always needs extra help to being a student with an outstanding ability to share with others. Additionally, at the end of her training she played an active role in advocating not only for herself, but also for others who will benefit from AT.

The classroom teacher, the principal, and the rest of the school staff are becoming more and more familiar with the programs and the promise that such programs hold for the academic achievement and personal development of their students with learning difficulties. Alex continues to work with Word Q and her Alphasmart Dana and all parties agree that she should continue to use Kurzweil 3000. Not only does the school now have it available in her classroom, but all teachers in the school board can access the technology. Kurzweil 3000 will offer many features of value to Alex throughout her school career. For example, in high school when she has many subjects for which she will have to write tests, she will be able to download notes from the program into a portable MP3 player which will allow her to study away from a computer terminal.

The occupational therapist has now worked with other students in Alex's class and recommended similar computer software and hardware, including Write Out Loud, Co-Writer, Dragon Naturally Speaking, and other Ontario Ministry of Education approved programs. Recommendations of free programs of interest to families include Read Please and Natural Reader. The Alphasmart Dana now is being recommended for student use and subsequently a school in the local board has purchased a classroom set for its students.

Did the intervention of AT have a noticeable effect on Alex's academic achievement or attitudes toward school? After her tutorial sessions with Mandy in 2005, Alex was proclaimed the "most improved student" in her school at the end of the year. At the end of one school year of sessions in 2006 with the pre-service teacher, she further developed her use of Kurzweil 3000 and learned Word Q together with the use of Alphasmart Dana, as recommended by the occupational therapist. She has maintained an overall average mark of B despite the increase in academic complexity and demands on her as a student as she progressed through the junior intermediate grades. As Alex's mother stated, "Alex maintains a love of school and her stress level is reduced by using technology."

At the end of June 2007, Alex received a computer award from her school. The other student who won this award was a student Alex tutored to use the computer and software Word Q and Kurzweil 3000. Alex received two additional awards during this school year: one was an achievement award and the other was an award for an essay she wrote and presented. She independently, with the use of Word Q and her Alphasmart Dana, wrote an essay describing to her class what she learned through the Drug and Alcohol Awareness program. Additionally, with the aid of Kurzweil 3000 she applied information to an essay from a book she was reading. She was one of three students who presented her essay to two different classes; projects such as this have become Alex's strength with the assistance of AT. All of her projects were presented in class and she received a grade of an A on each one - a testament to her strength in this area.

\section{Summary of Results and Conclusion}

Teaching Alex how to use AT as a tool to accommodate her learning needs has improved her academic achievement levels and fostered a positive self-concept with respect to her academic abilities. Teacher acceptance and use of AT with students with learning disabilities has 
become more widespread in Alex's classroom and school. Further projects of this nature in the school board should continue to educate teachers and moderate their perceptions of the applications and appropriateness of AT for students with exceptionalities as well as increase their willingness to accept its use for students with learning difficulties. Through the community servicelearning assignment in the Bachelor of Education program three other students with mild disabilities also showed significant improvement with the accommodation of AT.

Students have a variety of responses to interventions due to motivational, emotional, and behavioural variables (Berninger, Abbott, Whitaker, Sylvester, \& Nolen, 1995; Vauras, Rauhanummi, Kinnunen, \& Lepola, 1999). The intervention procedures in the current study should be further developed to help students with motivational-emotional-behavioural difficulties.

\section{References}

Ashton, T. (2006). Assistive technology. Journal of Special Education Technology, 21(3), 45-47.

Assistive Technology Act of 1998. Retrieved September 26, 2007, from http://section508.gov/docs/ AT1998.html

Berninger, V., Abbott, R., Whitaker, D., Sylvester, L., \& Nolen, S. (1995). Integrating low-and high-level skills in instructional protocols for writing disabilities. Learning Disabilities Quarterly, 18, 293309.

Blackhurst, A. E. (1997). Perspectives on technology in special education. Teaching Exceptional Children, 29(5), 41-48.

Borko, H., \& Putnam, R. (1998). Professional development and reform-based teaching: Introduction to theme issue. Teaching and Teacher Education, 14, 1-3.

Canadian Alliance for Community Service-Learning. (2007). What is Community Service-Learning? Retrieved January 26, 2007, from http://www.communityservicelearning.ca/en/welcome_what is.cfm

Conners, K. (1989). Conners' Rating Scale. Toronto, ON: MHS, Inc.

Cousin, G. (2005). Case study research. Journal of Geography in Higher Education, 29(3), 421-427.

Dunn, L., \& Dunn, L. (1997). Peabody Picture Vocabulary Test-III (PPVT-III). Toronto, ON: Pearson.

Edyburn, D. (2000). Assistive technology and students with mild disabilities. Focus on Exceptional Children, 32(9), 1.

Government of Canada (2007). APT glossary. Retrieved May 29, 2007, from http://www.boaa.gc.ca/ ap10005E.asp

Graham, S., \& MacArthur, C. (1988). Improving learning disabled students' skills at revising essays produced on a word processor: Self-instructional strategy training. Journal of Special Education, 22, $133-152$.

Jordan, D. (2000). Dyslexia Assessment Reading Program, second edition. Richmond Hill, ON: Psycan.

Lachar, D., \& Gruber, C. (1995). Personality Inventory for Youth. Richmond Hill, ON: Psycan.

Marino, M., Marino, E., \& Shaw, S. (2006). Making informed assistive technology decisions for students with high incidence disabilities. Teaching Exceptional Children, 38(6), 18-25.

Ministry of Children and Youth Services. (2006). Occupational therapy writing assessment. Sudbury, ON: Author.

National Center for Learning Disabilities (2007). Learning disability symptom checklist. http:// www.education.uiowa.edu/REACH/documents/LearningDisabilitiesChecklist--NCLD_001.pdf

National Youth Leadership Council. (2007). What is service learning? Retrieved June 5, 2007, from http://www.nylc.org/discover.cfm?oid=3152 
Ontario Human Rights Commission. (n.d.). The duty to accommodate. Retrieved October 16, 2007, from http://www.ohrc.on.ca/en/resources/Policies/PolicyDisAccom2?page=PolicyDisAccom2THE.html\#Heading 165

Ontario Ministry of Education. (1998). Regulation 181/98. Retrieved July 10, 2008, from http:// www.edu.gov.on.ca/ eng/general/elemsec/speced/hilites.html

Ontario Ministry of Education. (2005). Education for all: The report of the expert panel on literacy and numeracy instruction for students with special education needs, Kindergarten to Grade 6. Retrieved January 28, 2008, from http://www.edu.gov.on.ca/eng/document/reports/speced/ panel/index.html

Patrone, G., \& Pettapiece, R. (2007). Technology for individuals with special needs. Phi Delta Kappan, $88(7), \mathrm{C} 3-\mathrm{C} 3$.

Province of Ontario. (2001). The Ontarians with Disabilities Act. Ottawa, ON: Queen's Printer c. 32, s. 1. Retrieved July 10, 2008, from http://www.e-laws.gov.on.ca/html/source/statutes/english/2001/ elaws_src_s01032_e.htm

United States Assistive Technology Act. (1998). Retrieved July 10, 2008, from http:// www.rehabtool.com/ forum/discussions/1.html.

Vauras, M., Rauhanummi, T., Kinnunen, R., \& Lepola, J. (1999). Motivational vulnerability as a challenge for educational interventions. International Journal of Educational Research, 31, 515-531.

Wagner, R., Torgensen, J., \& Rashotte, C. (1999). Comprehensive Test of Phonological Processing. Richmond Hill, ON: Psycan.

Wechsler, D. (1991). Wechsler Individual Achievement Test Second Edition. Toronto, ON: Psychological Corporation.

Wechsler, D. (1991). Wechsler Intelligence Scale for Children Third Edition. Toronto, ON: Psychological Corporation.

World Health Organization. Disability and rehabilitation WHO action plan 2006-2011. Retrieved October 17, 2007, from http://www.who.int/disabilities/publications/dar_action_ plan_ 2006to2011.pdf

Yin, R. (2003). Case study research, design and methods (3rd ed.). Thousand Oaks, CA: Sage Publications.

\section{Author's Note}

Correspondence concerning this article should be addressed to Darlene Brackenreed, Ph. D., Nipissing University, 100 College Drive, North Bay, ON P1B 8L7.

E-mail: darleneb@nipissingu.ca 